\title{
COMPREENDENDO A
DEFICIÊNCIA PELA ÓPTICA DAS PROPOSTAS WINNICOTTIANAS
}

\author{
Maria Lúcia Toledo Moraes Amiralian
}

(@) surgiu de nossa compreensão de três conceitos básicos de Winnicott: a concepção do processo de desenvolvimento - a constituição do sujeito psíquico através da interação de um equipamento anátomo-fisiológico com o ambiente; a maneira de entender as relações objetais - pela transformação dos objetos subjetivos em objetos compartilhados, objetivamente percebidos - e o conceito de falso e verdadeiro self - o falso self se desenvendo como defesa às invasões do ambiente.

A análise desses conceitos levanos a refletir sobre as propostas de intervenção junto às pessoas com deficiência e sobre uma nova maneira de compreender temas sempre presentes nos trabalhos com deficientes como: "integração dos deficientes" , "pessoas portadoras de deficiência", "normalização" e "treinamento de atividades".

Embora Winnicott tenha sido fundamentalmente um grande terapeuta $\mathrm{e}$ dedicado grande parte de sua vida profissional ao atendimento de pacientes adultos, crianças, adolescentes, casos ambulatoriais - as chamadas consultas terapêuticas - e clientes com psicose, percebemos em seus escritos sua grande preocupação com a compreensão da natureza humana, sua constituição e desenvolvimento. Membro da chamada Escola Inglesa de Psicanálise entrou na psicanálise pela porta da pediatria, revelando desejo em aprofundar conhecimentos sobre o ser humano, não se contentando com explicações parciais a partir de enfoques específicos.

Suas idéias nos revelam um pensador crítico, reflexivo e criativo. Quando nos diz que, "Quase todos os aspectos do relacionamento entre pessoas totais foram abordados pelo próprio Freud, e de fato é muito dificil atualmente dar a isto qualquer contribuiçâo, a não ser que se consiga fazer uma exposição original daquilo que já é aceito" (1990, p. 54 ), vemos que, mesmo considerando a grande contribuição de Freud, acredita que suas propostas não dão conta da compreensão do desenvolvimento emocional no estágio mais primitivo do ser humano, antes do bebê já ter se torna- 
do uma pessoa total, e, assim, ao aprofundar os estudos psicanalíticos oferece-nos uma nova psicanálise, ou seja, uma nova maneira de entendermos a vida psíquica.

Winnicott não se dedicou especificamente à compreensão de crianças que apresentam deformidades físicas, embora tenha atendido algumas delas, ao contrário, enfatiza que suas reflexões referem-se ao desenvolvimento normal de bebês sadios, mas está implícito em seus textos a preocupação de criar uma teoria geral do desenvolvimento. "Minha esperança é que o que tenbo a dizer os ajude a colocar as outras coisas que ouvirem em relação com a teoria geral do desenvolvimento da personalidade bumana. Existe uma teoria geral que tem de deixar espaço para tudo, inclusive o que ainda não é conbecido e o que ainda não é considerado" (1994 a, p. 119).

Foi a partir desta afirmativa que nos interessamos em refletir sobre as implicações que lesões ou alterações em algum órgão ou função possam causar ao desenvolvimento do ser humano.

\section{A CONSTITUIÇÃO DO SELF}

Winnicott postula os fundamentos da vida psíquica em termos da constituição do self. Para ele o que se encontra na origem do ser é o potencial herdado, uma força vital para um contínuo vir a ser. "O que existe é um conjunto anatômico e fisiológico, $e$ a isto se acrescenta um potencial para o desenvolvimento de uma personalidade humana. Há uma tendência geral ao crescimento físico e ao desenvolvimento da parte psíquica da parceria psicossomática" (1994 b, p. 09).

Potencial que se realiza no encontro com o ambiente, que em um primeiro momento é identificado com a mãe. No processo do desenvolvimento o self tende a se constituir como uma unidade integrada, psicossomática e capaz de agir. Essas primeiras tarefas do bebê, integração, personalização e realização, vinculam-se a um estado de dependência absoluta não sentida pelo bebê como dependência, mas como um estado necessário para a continuidade do existir.

A partir de suas experiências o bebê, pela "elaboração imaginativa" de suas sensações, relacionadas à capacidade materna de atender as necessidades de seu filho, cria a psique paralelamente as primeiras tarefas já mencionadas.

Nesse processo que ocorre com todas as crianças, com deficiência ou não, vemos que a qualidade das interações primáriás mãe-bebê é o fator básico para um desenvolvimento sadio, considerado por Winnicott como o daqueles "que estão (pôr definição) mais próximos de serem aquilo que permite o equipamento com que vieram ao mundo" (1990, p. 37).

Todavia muitas vicissitudes ocorrem no encontro da mãe com 
seu bebê deficiente, e as primeiras tarefas do bebê, na fase de dependência absoluta, podem ficar prejudicadas, assim como muitas dificuldades serão sentidas pela mãe.

A mãe, que nesse momento já está fragilizada por um estado de sensibilidade aumentada, tem que se haver com a deficiência do filho que fará ressurgir uma gama de emoções e afetos relacionados à sua significação de deficiência. Além disso terá muitas dificuldades em compreender as necessidades de um filho deficiente. Dificuldades que irão interferir e, mesmo, em alguns momentos, impedir a realização de seu papel de "mãe devotada comum" que, como salienta Winnicott, é aquela que é capaz de identificar-se com seu bebê e nesta condição atender suas necessidades oferecendo-lhe "holding"1, "handling" e apresentando o mundo ao seu filho, no tempo e da maneira necessários

Todavia essa mãe nunca foi um bebê deficiente, mais ainda, talvez tenha muita dificuldade em imaginar-se deficiente, em sentir-se como uma pessoa que não enxerga, não escuta, ou não é capaz de realizar os movimentos apropriados.

Por outro lado o bebê, devido sua condição deficiente, manifestar-se-á de uma maneira incomum e desconhecida para a mãe, motivo de perturbação nesse momento difícil.

Embora seja a mãe o elemento desta parceria que, por ser uma personalidade já constituída, é a responsável pela interação mãe-filho, as atividades iniciais do bebê tem uma influência marcante nessa relação. Os movimentos do bebê não irão determinar a relação mãe-filho, mas serào os pontos sobre os quais a mãe se apoiará para estabelecer a "negociação contínua de experiências subjetiva" que, no dizer de Bollas (1992, p. 27), "mantêm coesos os rituais da necessidade psicossomática: a alimentação, a troca de fraldas, o acalmar, o brincar e o dormir"

Dessa forma constitui para a mãe um desafio desvelar as necessidades psicossomáticas de um filho com alterações neurológicas que com freqüência apresenta atividades descoordenadas e respostas instáveis à atividade materna, fator que poderá gerar um estado de extrema ansiedade na mãe, dificultando ainda mais seu encontro com o bebê. De maneira semelhante, se a criança for cega ou não escutar ela responderá menos e de forma incomum; se ela tiver uma deficiência mental poderá apresentar uma resposta tão frágil que a mãe não conseguirá decodificar, ou ainda, poderá ser uma criança que não apresente resposta alguma. Nesses desencontros a reação da mãe é de confusão, sentimentos de impotência diante do filho, ressentimento e raiva, às vezes mesmo, uma disposição excessiva à retaliação ou um desligamento e negação da função materna como um modo de defesa.

Quem já atendeu essas mães sabe com que freqüência ouvimos expressões como: "Não posso mais", "Não sei o que se passa com ele", "Ele parece nunca estar satisfeito", "Eu sei que ele não está bem, mas não posso deixar de me irritar". Esses sentimentos poderão interferir na sua oferta de um ambiente "suficientemente bom" e se houver uma demora muito grande para que eles encontrem uma negociação satisfatória, pode-se criar um círculo vicioso em que mãe e filho irritem-se mutuamente.

Esses desencontros dificultam as funções maternas de "holding", "handling" e apresentação do mundo, podendo causar falhas mais ou menos profundas nas tarefas básicas de integração, personalização e realização.

Essas dificuldades apontam para a importância de um atendimento pre- 
coce às mães de crianças com deficiência. Atendimento que deverá ter como objetivo básico dar apoio e sustentação a essas mães para que elas possam realizar com sucesso sua função intransferível.

O apoio às mães de crianças com deficiência, nesse momento difícil, é fundamental e creio, poderá prevenir muitos problemas, dificuldades e patologias que são encontrados em pessoas com deficiências.

Algumas reflexões neste momento nos ajudam a esclarecer certos pontos sobre o desenvolvimento de crianças com deficiência e sobre questões ligadas à própria deficiência.

Em primeiro lugar podemos afirmar que a saúde física e psíquica dessas crianças está em relação direta com nossa capacidade de atendermos suas necessidades, respeitando sua condição anátomo-fisiológica. Querer transformar uma criança com deficiência em uma criança que seja em tudo igual às crianças não deficientes é desrespeitar o seu "ser", impedindo a manifestação de seu potencial herdado e, ao contrário, exigindo dela não ser aquilo que é, mas aquilo que gostaríamos que fosse.

Seguindo esse raciocínio pareceme que o termo "normalização" nos aponta para uma não aceitação da pessoa como ela é, impondo-lhe a necessidade de desenvolver um "falso self", ou seja, um padrão defensivo de comportamento que a ajudará a responder de forma a satisfazer as exigências do ambiente familiar, escolar ou social mais amplo, mas que não favorecerá o desenvolvimento de seu verdadeiro self.

É importante assinalar, também, que não podemos considerar patológico o desenvolvimento diferente de uma criança deficiente antes de conhecermos qual é, na realidade, o seu padrão de desenvolvimento.

Segundo Winnicott, para as crian- ças com deformidades físicas a normalidade é a sua própria maneira de ser, tanto na sua forma como na sua função somática, pois elas têm tendência a supor que o que existe é o normal. "Tal como começa, assim tem de ser aceito, $e$ assim tem de ser amado. É uma questão de ser amado sem sançôes" (1994 c, p. 205).

Como diz Lins (s/d), ele só se dará conta de sua deficiência pela percepção e sentimento de fatores inexplicáveis, como, por exemplo, a atitude das pessoas ao seu redor. A experiência da deficiência, portanto, origina-se na maneira de ser da mãe. E podemos dizer, que a patologia se instalará quando não houver aceitação por parte da mãe do modo de ser de seu filho, quando não souber atender às suas necessidades $\mathrm{e}$ não souber quais as condições necessárias que lhes deverão ser oferecidas. Dizendo de outra forma, quando não puder aceitar, com amor, sua maneira própria de ser.

\section{O ESTABELECIMENTO DAS RELAÇÕES OBJETAIS}

Pensando agora na proposta de Winnicott sobre o estabelecimento das relações objetais, de como a criança transforma os fenômenos subjetivos em objetos compartilhados, objetivamente percebidos, observamos que muitos pontos obscuros podem ser clarificados no entendimento das pessoas com deficiência.

Para o autor o mundo interno é a área dos fenômenos subjetivos, povoada pelos objetos subjetivos, as primeiras criações do bebê. Esses objetos derivam da elaboração imaginativa das primeiras experiências, que como diz Winnnicott é a criação de um objeto que já está lá "esperando para ser criado e não encontrado... Isto tem que ser aceito 
como um paradoxo, e não resolvido por um refraseado que por seu brilhantismo pareça "eliminar o paradoxo" (1983, p.165).

Esta condição das experiências vividas lhe trará um sentimento de onipotência, oferecido pelo ambiente, fundamental para a adaptação ao princípio de realidade, na relação posterior com os objetos objetivamente percebidos. Se no momento anterior à fusão o sentimento mais importante é o da satisfação, que lhe proporcionará a ilusão da onipotência, após essa, são as frustrações gradativas, os elementos fundamentais para o estabelecimento das relações objetais.

Em seu texto "Comunicação $e$ falta de comunicação levando ao estudo de certos opostos" (1983), Winnicott nos diz que há um momento em que desenvolvimento significa alcançar a fusão, mas que um dos maiores avanços na progressão do desenvolvimento para a maturidade do ser humano é quando, após a fusão ser atingida, a falha ambiental, exercendo um papel positivo, permite ao lactente reconhecer um mundo que é repudiado, ou seja, a criação do não-eu. Este é um difícil processo gradativo em que o bebê vai criando o mundo externo.

O bebê que antes criou o seio que o amamentava, por tê-lo encontrado no momento certo e da maneira desejada, tendo assim a ilusão da onipotência, ao encontrar objetos imóveis, frente ao movimento oriundo do erotismo muscular e de forças irresistiveis, o repudia colocandò-o fora da área dos fenômenos subjetivos, o que lhe possibilita reconhecer um mundo de objetos que já estão lá, e por isso têm um valor em sí.

Mas, qual é o fator básico que permitirá ao bebê colocar fora os objetos subjetivos? Em seu texto "O Uso de um Objeto e o Relacionamento através de Identificaçôes" (1994 b), Winnicott nos diz que é a destruição do objeto, a agressão e as idéias a ela relacionadas que permitem ao bebê colocar objetos fora do self, fora da zona do controle onipotente, ao mesmo tempo em que o self começa a surgir como uma entidade separada. Sugar e morder um mamilo que se apresenta mais cheio ou mais vazio, ter contato com um pano mais áspero ou mais frio do que aquele de sua primeira mamada teórica levará a criança a repudiá-los.

São as falhas ambientais, na medida certa, que possibilitam a criação do mundo externo, assim como a capacidade da mãe em aceitar as agressões de seu bebê. Essas agressões não se constituem em pulsão de morte, mas sim, ações impiedosas (rutbless), sem ódio, mais uma açâo dirigida pelo seu instinto de vida, sua força vital. É a não retaliação da mãe às exigências impiedosas do bebê que lhe possibilitará a difícil transição do relacionar-se com objetos subjetivos para o relacionar-se com objetos percebidos objetivamente. Nesse momento o bebê abre mão de sua onipotência para reconhecer as qualidades da coisa em si.

Para as crianças com deficiência podemos supor muitas dificuldades. Como já dissemos o desencontro entre o bebê e sua mãe pode levá-la a retaliações quando as ações de seu filho, originadas do erotismo muscular, forem inconsistentes, confusas e incomuns, fazendo-o voltar-se para seu mundo interno, não encontrando o caminho para a percepção do mundo objetivo. Por outro lado suas próprias condições, restringindo seus movimentos, empobrece suas experiências e em conseqüência seu mundo subjetivo. Além disso, para as crianças com movimentos pobres ou incomuns, devido a alguma lesão neurológica, podemos pensar numa difícil expressão do erotismo muscular, o que não facilita seu encontro com os obje- 
tos, mas sim, uma permanência na ilusão do objeto subjetivo.

Nessa transição outra grande importância da mãe é como ela apresenta o mundo ao seu bebê, e para as crianças com deficiência esta é uma questão crucial.

Se por um lado a mãe apresenta a seu filho o mundo que ela conhece, um mundo de objetos conhecidos visual e auditivamente, as crianças com problemas sensoriais o percebem a partir de seu equipamento sensorial. Isto trará para essas crianças um problema a mais, além de ter que transformar objetos subjetivos em objetos percebidos objetivamente, terão que encontrar um caminho que estabeleça a semelhança entre objetos visual e auditivamente apresentados com as funções somáticas de que dispõe. Fica assim para a criança o encargo da interação com a mãe. Quando essa interação fica difícil as tarefas de inegração e personalização da criança ficam prejudicadas.

Creio que muitos comportamentos descritos como comuns às pessoas cegas podem ter sua origem nessa dificuldade. Os ceguismos, maneirismos comuns aos cegos como balançar a cabeça, esfregar os olhos, balançar as mãos etc... explicam-se por um retorno ao seu mundo interno e uma dificuldade em relacionar-se com o mundo externo. Dificuldade derivada da incompreensão do mundo externo pela falha na interação e consequente ausência de relações estabelecidas entre as informações visuais e suas percepções auditivas e táteis cinestésicas.

\section{O FALSO SELF}

Mas, creio que o aspecto mais importante do desenvolvimento das pessoas com deficiência é a necessidade de desenvolverem uma extensa organiza- ção de falso self para serem aceitas. Em meu trabalho com clientes com deficiência visual o que mais me têm chamado a atenção é a dificuldade em manifestarem seu verdadeiro self, em aceitarem-se como pessoas cegas e em acreditarem em suas percepções.

Joana uma jovem cega de 24 anos, em uma sessão de Desenhos-Estórias faz uma figura humana e diz: "Está ficando esquisito. Acho que nem sei o que estou fazendo". Eu disse: "Eu acho que sabe sim. - Por que? - Porque parece que você está fazendo alguma coisa que está em sua cabeça. (sua atitude de concentração no desenho foi o que me levou a fazer esse aparte) - Ah! Ficou muito feio. Ah! Vou deixar assim. É uma pessoa que eu queria desenhar aqui. É uma pessoa que nunca vi; não conheço, nunca cruzei. É uma pessoa que não tinha um lugar firme para pisar, de repente aparece na minha frente e eu não posso fazer nada por ela; eu desenhei. Pelo menos a presença dela eu notei".

Vemos claramente que Joana nos fala de seu eu profundo, seu verdadeiro self, que ela não conhece e que defende por não ter um lugar seguro para pisar.

Outra paciente nos fala de sua falta de confiança em suas percepções. Uma adolescente de 15 anos, com cegueira congênita que sempre passa suas férias com a família em sua casa à beiramar, nos diz: - "Há outra coisa que eu gostaria de conhecer, seria o mar, montes de onda, ficar mergulhando". Digo: - "Tem curiosidade de conhecer?" Talvez minha entonação tenha mostrado à Carla minha dúvida sobre seu desconhecimento desses objetos. Fica quieta, não assume a desconfiança com suas percepções e diz: - "Não é bem conhecer, é saber como o mar tem as ondas, como o mar não se esparrama".

Carla nos mostra, tanto sua falta de confiança em suas possibilidades perceptivas como a necessidade de mos- 
trar-se como uma jovem igual as outras. Portanto, expressando um falso self para poder conviver com os videntes, sem revelar as dificuldades peculiares à cegueira.

Esses e muitos outros exemplos mostram a compacta organização de falso self que as pessoas com deficiência precisam desenvolver. Acredito que isso ocorre, principalmente por nossas atitudes que revelam um desejo de que elas sejam iguais a nós. E o "treinamento de atividades", tão comum nas intervenções às pessoas com deficiência, exemplifica essa postura

Nisto creio está a responsabilidade que nós, profissionais e sociedade, temos em poder aceitar e conviver com pessoas que são diferentes, permitindo a expressão de seu verdadeiro self.

Essas são algumas reflexões sobre o desenvolvimento e as intervenções junto a pessoas com deficiência, apenas as primeiras, mas creio que muitas outras devem ser feitas e espero que pessoas interessadas nesta área possam vir a colaborar comigo, continuando esse trabalho e trazendo contribuições valiosas para o estudo das pessoas com deficiência.

\section{REFERÊNCIAS BIBLIOGRÁFICAS}

BOLLAS, C. (1992). A Sombra do Objeto. Rio de Janeiro: Imago Editora.

LINS, M.I.A. A Representaçâo do corpo na criança, texto mimiografado.

WINNICOTT, D.W. (1983). Comunicação e falta de comunicação levando ao estudo de certos opostos. In: O Ambiente e os Processos de Maturação: estudos sobre a teoria do desenvolvimento emocional. Porto Alegre: Artes Médicas Sul. [1963]

(1990). Natureza Humana.

Rio de Janeiro: Imago Editora.

(1994a). Uma Nova Luz

sobre o Pensar Infantil. In: Winnicott, C., Shepherd, R. e Davis, M. Exploraçôes Psicanalíticas. Porto Alegre: Artes Médicas Sul. [1965]

(1994b) O Uso de um

Objeto e o Relacionamento através de Identificações. In: Winnicott, C., Shepherd, R. e Davis, M., Explorações Psicanalíticas. Porto Alegre: Artes Médicas Sul. [1968]

(1994c) Sobre as Bases para

o Self no Corpo. In: Winnicott, C., Shepherd, R. e Davis, M. Exploraçôes Psicanalíticas. Porto Alegre: Artes Médicas Sul. [1970]

\section{NOTAS}

1 As expressões "holding" e "handling" geralmente não são traduzidas por não haver em português uma palavra que expresse exatamente o pensamento de Winnicott. Holding significa, tanto o segurar e o acalentar físicos como a segurança afetiva emocional que a mãe deve proprorcionar ao seu filho. E handling, de forma semelhante, significa o manipular e o manusear físicos, mas também oferecer experiências corporais significativas à personalização. 